\title{
SISTEM PAKAR PADA TANAMAN APOTEK HIDUP UNTUK PENGOBATAN ALTERNATIF MENGGUNAKAN METODE CERTAINTY FACTOR
}

\author{
Dimas Satriadi ${ }^{1}$, Anton Setiawan H. ${ }^{2}$, Yuliani Indrianingsih ${ }^{3}$ \\ Departemen Informatika \\ Sekolah Tinggi Teknologi Adisutjipto Yogyakarta \\ anton@stta.ac.id ${ }^{2}$,yulistta@gmail.com ${ }^{3}$
}

\begin{abstract}
Medical treatment using herbal plants rarely utilized by the society, because most of them didn't know the benefit inside herbal plants. therefore needed an application to educate the society about herbal life. Application system was a product of research by a herbal expert using certainty factor. Certainty factor method was a method that to believe on an event based on expert judment. Besides educating society about the benefit of herbal plants, the expert system could help to provide a consultation. Result of expert system consultation with certainty factor was to minimize uncertainty in medical treatment using herbal plants.
\end{abstract}

Keywords: Medical Plants, Certainty Factor (CF), Herbal, Expert System.

\section{Pendahuluan}

Apotek hidup adalah pemanfaatan sebagian tanah untuk ditanami tanaman obat-obatan untuk keperluan sehari-hari. Apotek hidup biasa disebut dengan tanaman obat keluarga (TOGA) yang hakekatnya merupakan sebidang tanah baik dihalaman rumah, ladang ataupun kebun yang digunakan untuk membudidayakan tanaman yang berkhasiat sebagai obat. Dalam upaya pelayanan kesehatan, ketersediaan obat dalam jenis yang lengkap, jumlah yang cukup, terjamin khasiatnya, dengan biaya yang murah merupakan permasalahan yang sulit dipecahkan. Dengan adanya permasalah tersebut menteri kesehatan dalam undang - undang No. 23 tahun 1992 tentang kesehatan disebutkan bahwa obat tradisional adalah bahan atau ramuan yang berupa tumbuhan yang secara turun temurun telah digunakan untuk pengobatan berdasarkan pengalaman. Pada jaman sekarang ini masyarakat umumnya bisa dengan mudah mendapatkan informasi dalam berbagai hal, seperti konsultasi atau mencari solusi. Hal inilah yang mendorong pembangunan sebuah sistem pakar tanaman pada apotek hidup untuk pengobatan alternatif menggunakan metode certainty factor dengan tujuan membantu meminimalisir ketidakpastian pada pengobatan menggunakan tanaman herbal.

\section{Metode Penelitian}

\subsection{Apotek Hidup}

Apotek hidup adalah pemanfaatan sebagian tanah untuk ditanami tanaman obat-obatan untuk keperluan sehari-hari. Apotek hidup biasa disebut dengan tanaman obat keluarga (TOGA) yang hakekatnya merupakan sebidang tanah baik dihalaman rumah, ladang ataupun kebun yang digunakan untuk membudidayakan tanaman yang berkhasiat sebagai obat

\subsection{Sistem Pakar}

Sistem pakar merupakan cabang dari AI (Artificial Inteligent) yang membuat ekstensi khusus untuk spesialisasi pengetahuan guna memecahkan suatu permasalah pada human expert. sistem pakar adalah sistem yang berusaha mengadopsi pengetahuan manusia ke komputer yang dirancang untuk memodelkan kemampuan menyelesaikan masalah seperti layaknya seorang pakar. 


\subsection{Certainty Factor}

Faktor kepastian (certainty factor) menyatakan kepercayaan dalam sebuah kejadian (atau fakta atau hipotesis) berdasarkan bukti atau penilaian pakar.

$$
\mathrm{CF}(\mathrm{h}, \mathrm{e})=\mathrm{MB}(\mathrm{h}, \mathrm{e})-\mathrm{MD}(\mathrm{h}, \mathrm{e})
$$

$\mathrm{CF}(\mathrm{h}, \mathrm{e}) \quad$ : certainty factor.

MB (h,e) : ukuran kepercayaan (measure of increased belief) terhadap hipotesis $\mathrm{H}$ yang jika diberikan evidence E (antara 0 dan 1$)$.

$\mathrm{MD}(\mathrm{h}, \mathrm{e}) \quad$ : ukuran ketidakpercayaan (measure og increased disbelief) terhadap evidence $\mathrm{H}$, jika diberikan evidence $\mathrm{E}$ (antara 0 dan 1$)$.

\subsection{Metode Perancangan Perangkat Lunak}

Metode dengan merancang form interface untuk Sistem Pakar Tanaman Pada Apotek Hidup Untuk Pengobatan Alternatif.

Teknik representasi aplikasi sistem pakar pada apotek hidup untuk pengobatan alternatif adalah dengan kaidah produksi berupa aturan (rule) yang berupa IF (kondisi) THEN (aksi). IF (kondisi) merupakan bagian dari awal yang mengekspresikan situasu. THEN (aksi) merupakan bagian yang menyatakan suatu tindakan tertentu yang diharapkan jika situasi bernilai besar. Dibawah ini adalah kaidah produksi untuk merepresentasikan pengetahuan atau aturan (rule) dalam pengembangan aplikasi sistem pakar pada apotek hidup untuk pengobatan alternatif.

Tabel 1. Representasi Pengetahuan.

\begin{tabular}{|l|l|}
\hline No. & \multicolumn{1}{|c|}{ Aturan (Rule) } \\
\hline 1. & IF alang-alang THEN batuk darah OR sesak nafas OR mimisan. \\
\hline 2. & $\begin{array}{l}\text { IF belimbing manis THEN bisul OR sakit kepala OR radang tenggorokan OR } \\
\text { infeksi saluran pernafasan OR batuk berdahak. }\end{array}$ \\
\hline 3. & $\begin{array}{l}\text { IF belimbing wuluh THEN batuk berdahak OR tekanan darah tinggi OR } \\
\text { gondongan OR jerawat. }\end{array}$ \\
\hline 4. & IF brotowali THEN gatal-gatal OR demam OR kencing manis. \\
\hline 5. & $\begin{array}{l}\text { IF bidara upas THEN gatal-gatal OR radang tenggorokan OR batuk berdahak } \\
\text { OR demam. }\end{array}$ \\
\hline 6. & IF kamboja THEN gatal-gatal OR demam. \\
\hline 7. & IF lengkuas THEN bisul OR batuk berdahak OR eksim OR jerawat \\
\hline 8. & $\begin{array}{l}\text { IF sambiloto THEN gatal-gatal OR demam OR kencing manis OR tekanan } \\
\text { darah tinggi OR liver OR batuk rejan }\end{array}$ \\
\hline 9. & $\begin{array}{l}\text { IF mengkudu THEN sariawan OR gondongan OR tekanan darah tinggi OR } \\
\text { eksim OR radang amandel. }\end{array}$ \\
\hline 10. & $\begin{array}{l}\text { IF pegagan THEN demam OR batuk darah OR tekanan darah tinggi OR tbc } \\
\text { paru-paru OR liver OR mimisan OR radang amandel. }\end{array}$ \\
\hline 11. & $\begin{array}{l}\text { IF kumis kucing THEN tekanan darah tinggi OR demam OR sakit ginjal OR } \\
\text { kencing manis. }\end{array}$ \\
\hline 12. & $\begin{array}{l}\text { IF temulawak THEN batu empedu OR tekanan darah tinggi OR sakit kuning } \\
\text { OR maag. }\end{array}$ \\
\hline 13. & IF jeruk nipis THEN demam OR batuk berdahak OR kurang darah. \\
\hline
\end{tabular}

\section{Hasil dan Pembahasan}

Implementasi dari aplikasi sistem pakar ini dilakukan menggunakan bahasa pemograman PHP dengan database Oracle, sebagai berikut : 


\subsection{Beranda}

Menu beranda merupakan halaman utama aplikasi sistem pakar tanaman pada apotek hidup untuk pengobatan alternatif.

$\Theta_{\text {APOIKH }}^{R}$

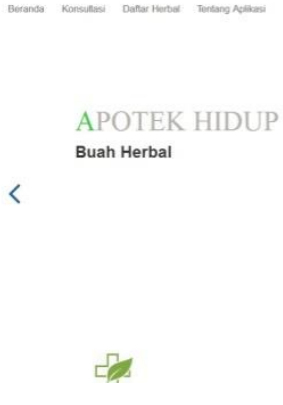

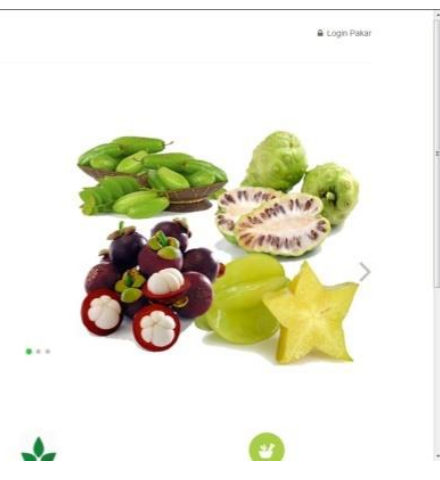

Gambar 1. Tampilan Beranda

\subsection{Sub Menu Pakar}

\subsubsection{Form Tambah Data Herbal}

Tambah data herbal merupakan form yang hanya dilakukan oleh pakar. Form ini terdapat kolom kode, nama, deskripsi, dan manfaat. Pada kolom kode terisi secara otomatis dan tidak dapat di ubah.

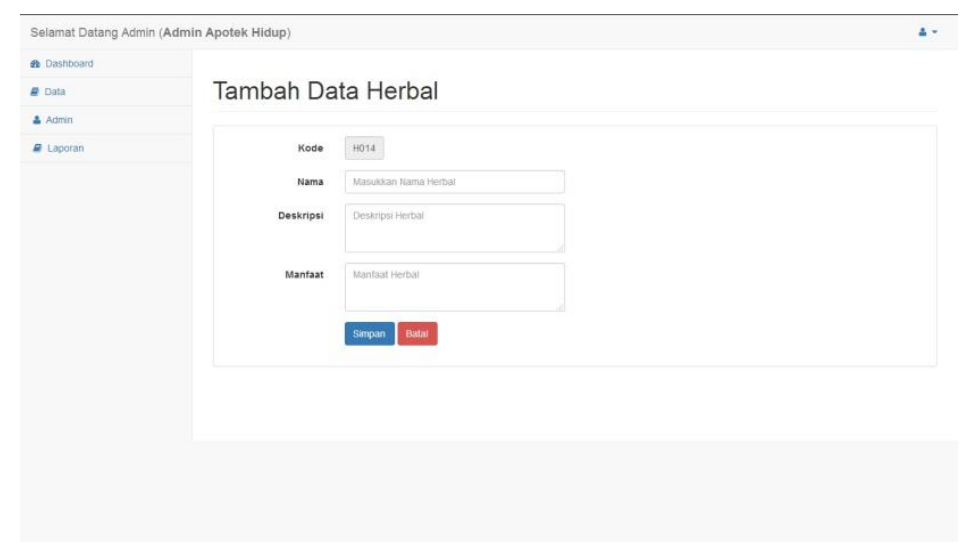

Gambar 2. Form Tambah Data Herbal

\subsubsection{Form Data Herbal}

Data herbal adalah submenu dari menu data yang berisi data-data herbal. Pada form data herbal terdapat tombol tambah data dan opsi edit data dan hapus data pada tabel.

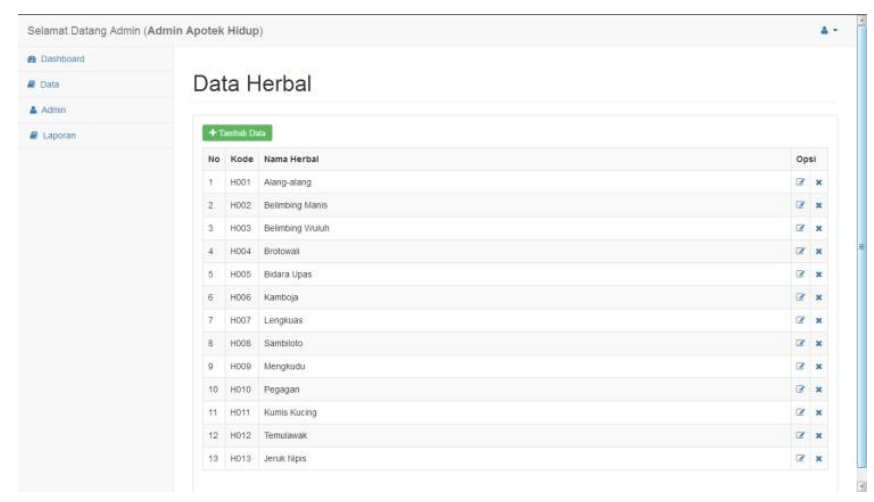

Gambar 3. Form Data Herbal 


\subsubsection{Form Tambah Data penyakit}

Tambah data penyakit merupakan form yang berisi kolom kode, nama, dan gejala. Pada kolom kode terisi secara otomatis dan tidak dapat di ubah.

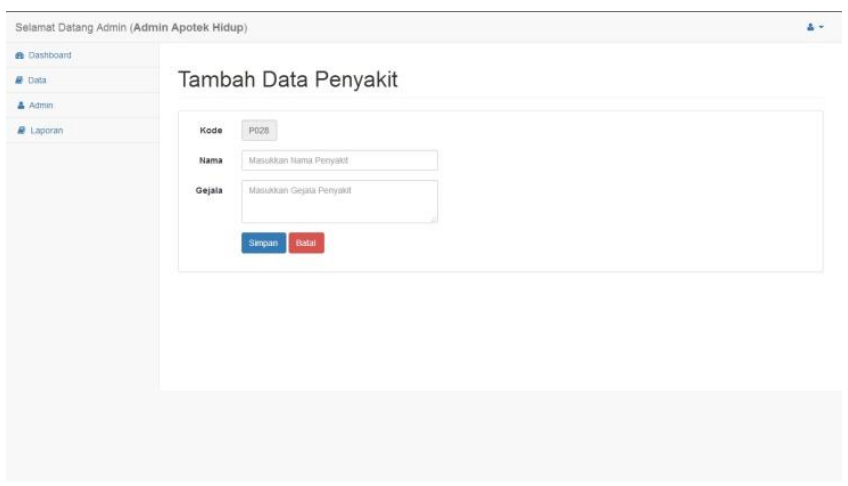

Gambar 4. Form Tambah Data Penyakit

\subsubsection{Form Data Penyakit}

Data penyakit adalah submenu dari menu data yang berisi data-data penyakit. Pada form data penyakit terdapat tombol tambah data dan opsi edit data dan hapus data pada tabel.

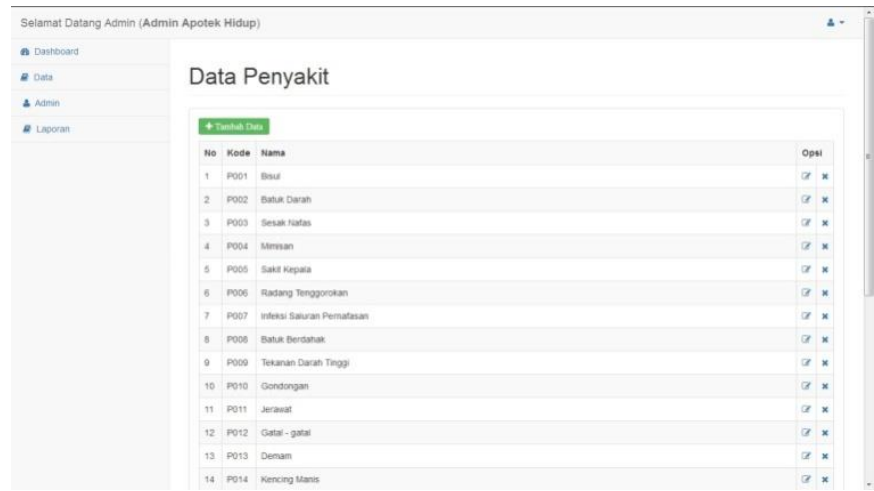

Gambar 5. Form Data Penyakit

\subsubsection{Form Tambah Data Relasi}

Tambah data relasi merupakan form yang berisi kolom herbal, penyakit, nilai kepastian (MB), nilai ketidakpastian (MD), dan cara pengobatan. Kolom herbal dan penyakit merupakan data yang diambil dari database pada tabel herbal dan penyakit yang saling berelasi.

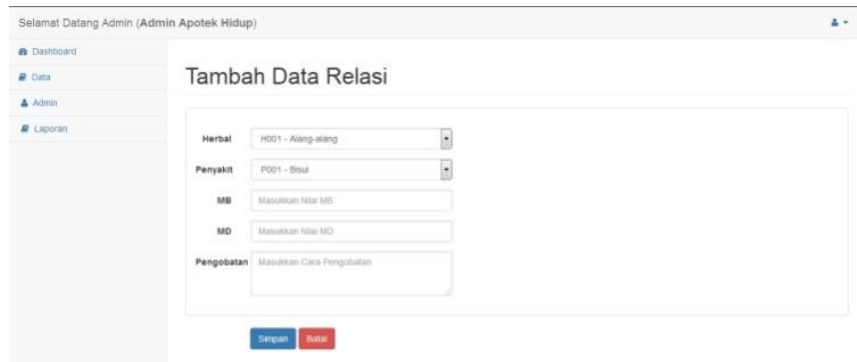

Gambar 6. Form Tambah Data Relasi 


\subsubsection{Form Data Relasi}

Data relasi adalah submenu dari menu data yang berisi data-data relasi antara data herbal dan data penyakit. Pada form data relasi terdapat tombol tambah data dan opsi edit data dan hapus data pada tabel.

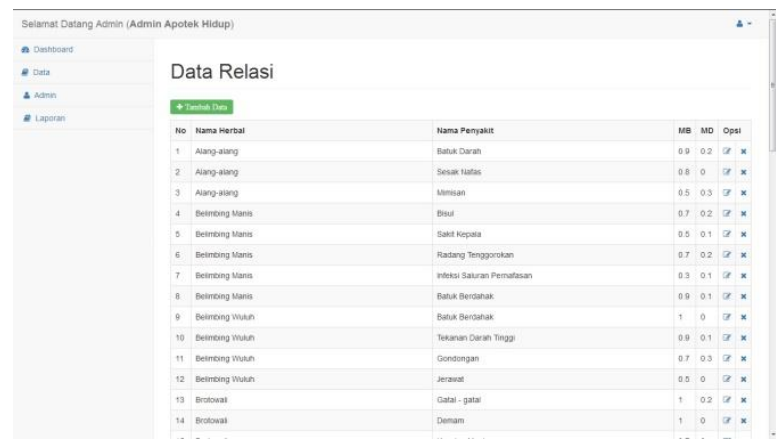

Gambar 7. Form Data Relasi

\subsection{Sub Menu Konsultasi}

\subsubsection{Form Konsultasi}

Konsultasi merupakan halaman untuk user melakukan analisis tentang tanaman herbal. Dalam menu konsultasi, user melakukan pengisian nama dan memilih tanaman herbal.

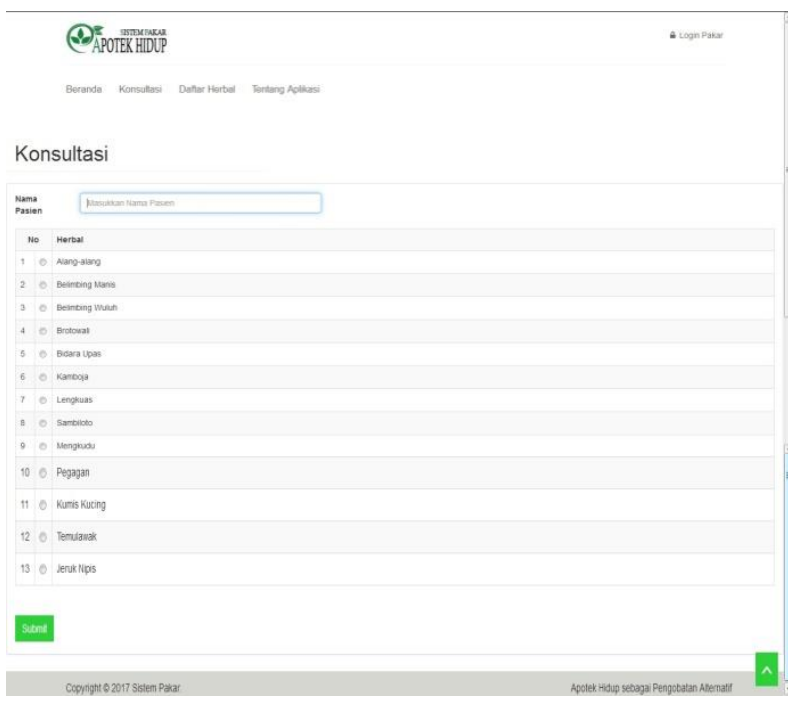

Gambar 8. Form Konsultasi user

\subsubsection{Form Hasil Konsultasi}

Setelah melakukan input nama dan memilih herbal, user akan mendapatkan hasil konsultasi yang berisi nama yang di input, herbal yang dipilih, dan beberapa penyakit yang sesuai dengan herbal yang dipilih yang sudah direlasikan. Beberapa penyakit yang muncul akan dipilih satu dengan nilai kepercayaan tertinggi.

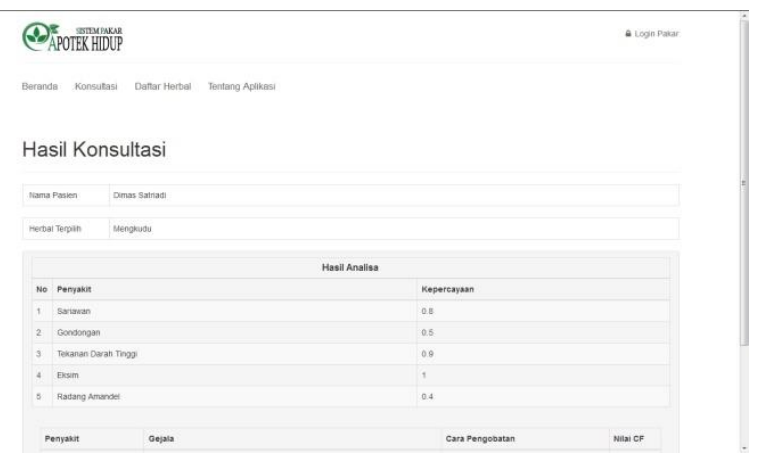




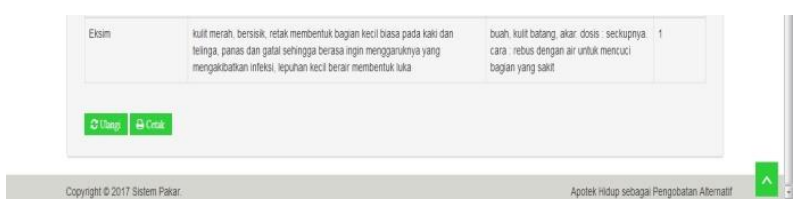

Gambar 9. Form Hasil Konsultasi

\subsubsection{Form Cetak Hasil Konsultasi}

Cetak hasil konsultasi merupakan form ketika user menekan tombol cetak pada hasil konsultasi. Cetak hasil konsultasi ini berisi nama, herbal, dan penyakit dengan nilai kepercayaan tertinggi serta gejala dan cara pengobatannya.

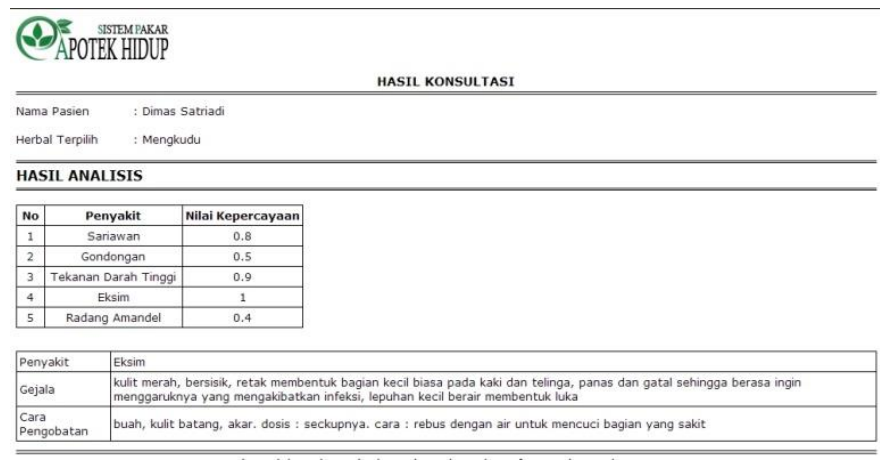

Gambar 10. Form Cetak Hasil Konsultasi

\section{Kesimpulan}

1. Perangkat lunak yang dihasilkan dapat membantu masyarakat untuk mengetahui manfaat tanaman herbal dan penggunaan tanaman herbal sebagai pengobatan alternatif.

2. Penerapan metode certainty factor yang digunakan pada sistem pakar pada tanaman apotek hidup untuk pengobatan alternatif memiliki hasil tingkat kepastian sebagai pengobatan alternatif yang pada dasarnya aplikasi ini tidak mengetahui herbal apa yang lebih cocok untuk pengobatan beberapa jenis penyakit.

3. Aplikasi sistem pakar dengan metode certainty factor ini dapat membantu meminimalisir ketidakpastian pada pengobatan menggunakan tanaman herbal.

\section{Daftar Pustaka}

[1]. Fauzi, Arif. 2017. Aneka Tanaman Obat Dan Khasiatnya. Yogyakarta : Media Pressindo.

[2]. Kusumadewi, Sri. 2003. Artificial Intelligence (Teknik Dan Aplikasi). Yogyakarta : Graha Ilmu.

[3]. Nugroho, Bunafit. 2014. Aplikasi Sistem Pakar Dengan PHP Dan Editor Dreamweaver. Yogyakarta : Gava Media.

[4]. Nusantara, Ariobimo. 2008. Tumbuhan Untuk Pengobatan 87 Jenis Penyakit Dengan Penanganan Herbal. Jakarta : Grasindo.

[5]. Raharjo, Budi. 2011. Belajar Otodidak Pemograman Web Dengan PHP + Oracle. Bandung : INFORMATIKA.

[6]. Ahmad Ramdhani, dkk. 2015. Pengembangan Sistem Pakar Untuk Diagnosa Penyakit Hepatitis Berbasis Web Menggunakan Metode Certainty Factor. Semarang : Jurnal Teknologi dan Sistem Komputer, Vol 3,No. 1, 
http://jtsiskom.undip.ac.id/index.php/jtsiskom/article/viewFile/11975/11629, diakses tanggal 20 Mei 2017.

[7]. Dodi Harto. 2013. Perancangan Sistem Pakar Untuk Mengidentifikasi Penyakit Pada Tanaman Semangka Dengan Menggunakan Metode Certainty Factor. Medan : Pelita Informatika Budi Darma. Vol IV, Nomor 2, www.academia.edu/download/49224529/425.pdf, diakses pada tanggal 5 Juni 2017.

[8]. Kusrini. 2006. Kuantifikasi Pertanyaan Untuk Mendapatkan Certainty Factor Pengguna Pada Aplikasi Sistem Pakar Untuk Diagnosis Penyakit. Yogyakarta : Jurnal Komputer Dan Sistem Intelijen, https://www.researchgate.net/profile/Kusrini_Kusrini/publication/265186139_KUANTIFIK ASI_PERTANYAAN_UNTUK_MENDAPATKAN_CERTAINTY_FACTOR_PENGGUNA_P ADA_APLIKASI_SISTEM_PAKAR_UNTUK_DIAGNOSIS_PENYAKIT/links/5602358308a ecb0ce881b438/KUANTIFIKASI-PERTANYAAN-UNTUK-MENDAPATKAN-CERTAINTYFACTOR-PENGGUNA-PADA-APLIKASI-SISTEM-PAKAR-UNTUK-DIAGNOSISPENYAKIT.pdf, diakses tanggal 6 Juni 2017.

[9]. Tuswanto Dan Abdul Fadlil. 2013. Sistem Pakar Untuk Mendiagnosa Hama Dan Penyakit Tanaman Bawang Merah Menggunakan Certainty Factor. Yogyakarta : Jurnal Sarjana Teknik Informatika. Vol 1, Nomor 1, http://www.jogjapress.com/index.php/JSTIF/article/download/1492/1005, diakses tanggal 19 Mei 2017. 